\title{
O CONHECIMENTO ESCOLAR COMO REIMAGINAÇÃO DA CULTURA: ARTICULANDO DIFERENÇAS A PARTIR DA ESCOLA
}

\author{
Luis Paulo Cruz Borges ${ }^{1}$
}

\section{RESUMO}

O conhecimento escolar como reimaginação da cultura constitui o objeto de estudo deste ensaio. Com ele busca-se articular o debate em torno do eixo: currículo, identidade e diversidade/diferença, entendendo a centralidade do conhecimento no jogo político na atualidade. A escola e o currículo, aqui, são entendidos como produtores de diferenças. O conceito de diferença é requerido como permanente mote de produção de subjetividades nos processos de enunciação da própria ação cultural (BHABHA, 2007). Assim, num primeiro momento conceitua-se o conhecimento escolar, entre o crítico e o pós-crítico, entendo que tais dimensões estão pautadas a partir da ideia da escola como produtora de diferença. Argumenta-se que o conhecimento escolar é (re)imaginação da cultura. No segundo momento, trabalha-se a partir da ideia de que a escola moderna está sob rasura e vem apresentando possibilidades analíticas importantes para repensarmos o papel do conhecimento num projeto de disputa de significação e hegemonias. À guisa de conclusão, assume-se que a reimaginação do conhecimento, e da própria escola, pode ser encarada como uma política de produção curricular.

Palavras-chave: Conhecimento escolar. Escola. Cultura. Currículo e diferença.

\begin{abstract}
School knowledge as a reimagination of culture is the object of study of this essay. It seeks to articulate the debate around the axis: curriculum, identity and diversity / difference, understanding the centrality of knowledge in today's political game. The school and curriculum here are understood to be producers of differences. The concept of difference is required as a permanent motto of the production of subjectivities in the processes of enunciation of cultural action itself (BHABHA, 2007). Thus, in a first moment the school knowledge is conceptualized, between the critic and the post-critical, I understand that these dimensions are based on the idea of the school as producer of difference. It is argued that school knowledge is (re) imagination of culture. In the second moment, we work on the idea that the modern school is undergoing shaving and has presented important analytical possibilities to rethink the role of knowledge in a project of dispute of signification and hegemonies. As a conclusion, it is assumed that the reimagining of knowledge, and of the school itself, can be seen as a curricular production policy. Keywords: School knowledge. School. Culture. Curriculum and difference.
\end{abstract}

\footnotetext{
${ }^{1}$ Professor do Instituo de Aplicação Fernando Rodrigues Silveira da Universidade do Estado do Rio de Janeiro (CAp-UERJ).
} 


\section{INTRODUÇÃO}

O tempo presente tem sido revelador de desafios em que grandes utopias, certezas e conviç̧ões estão postos em xeque. A via única de possibilidade está sendo confrontada com projetos em disputas que tem se apresentado à sociedade na arena política e social. Também mudam-se os fluxos globais e transnacionais, alarga-se a temporalidade, mas comprime-se os espaços, enfim, espaços-tempos entram em confrontos no âmbito local e global. Relativiza-se a dimensão da própria vida humano-social e dos direitos sociais. A guerra gera conflitos internos e externos, observa-se grandes fluxos migratórios. Ressurgem antigos projetos de sociedade, alguns calcados no conservadorismo extremo, já outros num proselitismo sem fim.

Importantes desafios, ligados às temáticas da realidade social, como as relações entre pluralismo e relativismo; o universal e o particular; o público e o privado; o profano e sagrado; sucesso e fracasso escolar; igualdade e desigualdade; mesmice e diferença; o local e global, entre outros, emergem num interstício entre Cultura e Educação (CANDAU, 2008). Nesse cenário, percebe-se a disputa de projetos como o Escola Sem Partido, Escola Livre, Escola Sem Mordaça, Movimentos juvenis de ocupação e desocupação, Movimento do Povo Livre e Sem Medo, Movimento Anarquista, Movimento do Passe Livre, Movimento do Brasil sem Corrupção, entre outros. Justifica-se, também, a criação de uma Base Nacional Curricular Comum que tenta articular e fixar identidades, aprisionar sentidos, enfim, controlar atos. Criam-se formas de controle negociado para os sujeitos da/na escola. Mas, também, propagam-se horizontes de "qualidade" e "transformação" como forma de melhoria do que está posto ao modelo de "fracasso" da escola brasileira, sobretudo a pública. Reverberam-se as ideias de neutralidade e cientificidade, enfim, de modelos salvíficos para a educação das infâncias e juventudes calcados no conhecimento.

É no contexto descrito acima que o presente texto tem como objetivo articular o debate em torno do eixo: currículo, identidade e diversidade/diferença, entendo a centralidade do conhecimento no jogo político na atualidade. Parte-se de uma problematização sobre inúmeras possibilidades de dizer os sentidos do conhecimento escolar e da própria escola numa perspectiva de centralidade da cultura (HALL, 1997) e da cultura como fluxo (BHABHA, 2007; APPADURAI, 2007, 2010). A escola e o currículo, aqui, são entendidos como produtores de 
diferenças. O conceito de diferença é requerido como permanente mote de produção de subjetividades nos processos de enunciação da própria ação cultural (BHABHA, 2007).

A tensão posta, no século XX, no ideário escolar de universalização da educação básica e, também, de redemocratização do país revela pontos nodais no processo de luta por demandas sociais e econômicas. Assim, no bojo de tais discussões está posto o acirramento da ideia de pluralidade cultural e o surgimento da preocupação de discursos sobre cultura e diferença que medeiam o conhecimento na esfera escolar (MACEDO, 2014).

Diferença numa perspectiva estruturalista é encarada como diferença entre algo que já preexiste. Nas palavras de Macedo (2014, p. 87), é “uma diferença que pressupõe partilhamento de traços comuns entre aquilo que será diferenciado". Dessa forma, será sempre uma diferença que compara preexistentes já diferentes, que normatiza. Contudo, em contraposição a tal perspectiva, assume-se, então, a ideia de que diferença é diferença em si, numa perspectiva pósestrutural, em que "não há diferentes a serem tornados iguais e noções como reconhecimento e redistribuição deixam de fazer sentido" (MACEDO, 2014, p. 95). A diferença é différance, é enunciação, sem fixações. A autora ainda argumenta que "essa diferença (em si) não inferioriza, ao contrário ela é condição de surgimento do sujeito" (idem, p. 100).

Ainda com a autora, a diferença entre está filiada a uma concepção de cultura como tradição a ser ensinada e com sentidos produzidos cotidianamente na escola. Desse modo, o debate proposto por Forquin (1993, p.167) versa sobre a cultura da escola como "um mundo social, que tem suas características de vida próprias, seus ritmos e seus ritos, seu imaginário, seus modos próprios de regulação e de transgressão, seu regime próprio de produção e de gestão de símbolos". Constitui uma concepção de tradição que universaliza, e quiçá essencializa, processos postos no projeto educacional da modernidade. Processos estes que estão imbricados à ideia de conhecimento escolar.

Pereira (2016) sinaliza que o projeto de escola moderna assumiu o ideal de instituição responsável pela transmissão e propagação da chamada “cultura universal”. No âmbito da própria escola, ainda na esteira de Forquin (1993), a ideia de cultura transmuta-se numa cultura escolar, ou seja, em "um conjunto de conteúdos cognitivos e símbolos que selecionados, organizados, 'normalizados', rotinizados, sob efeitos de imperativos de didatização, constituem habitualmente o objeto de uma transmissão deliberada no contexto das escolas" (FORQUIN, 1993, p. 167). Tal 
cultura escolar vem fixando sentidos sobre o que seria também o conhecimento presente no âmbito escolar.

Postas tais considerações, é mister pensar a escola como lugar de contradições e tensões, em que o questionamento sobre o conhecimento escolar, sua produção de sentidos e significados, recai sobre a própria instituição. Ao passo que a escola reproduz discursos e práticas, ela também é produtora de sentidos desses discursos e práticas postas à vida social. Assim, entende-se a escola como cenário e palco, como protagonista e coadjuvante, concomitantemente. Nesse contexto, ainda é preciso compreender práticas e saberes escolares como forma analítica da própria instituição em pauta, entendida como produtora de diferenças.

O texto em tela apresenta e problematiza, no primeiro momento, o conhecimento escolar que tensionado entre o crítico e o pós-crítico ${ }^{2}$ desliza sentidos sobre suas próprias definições. Já em um segundo momento, volta-se o olhar para a escola, entendida como um projeto da própria modernidade que pretende fixar sentidos sobre quais conhecimentos são ensináveis, mas que, $s o b$ rasura, nos possibilita compreendê-la na fronteira. Argumenta-se que a reimaginação da escola é posta em pauta no próprio jogo político de disputas presente hoje na esfera local e global sobre o sentido e o questionamento de qual seria função social da escola, em especial a escola para as classes populares. Por fim, à guisa de conclusão deste artigo, retorna-se a defesa da ideia, mesmo que contingencial, de que o conhecimento escolar, entendido como atos de significação, é agência cultural criadora de modos de subjetivação e justiça social permitindo que o Outro exista e resista em sua dimensão política, humana e social.

\section{O conhecimento escolar conceitualmente: entre o crítico e o pós-crítico}

"Proponho, então, que as relações entre conhecimento escolar e conhecimento cientifico sejam pensadas da perspectiva do pluralismo cultural. Um pluralismo que pressupõe questionamentos de um saber outro, negociações de sentidos e significados e conflitos entre finalidades distintas"(LOPES, 2007, p. 202).

\footnotetext{
${ }^{2}$ De acordo com Lopes (2013, p.09 ) "No campo do currículo, a expressão teorias pós-críticas é utilizada para se referir às teorias que questionam os pressupostos das teorias críticas, marcadas pelas influências do marxismo, da Escola de Frankfurt e em alguma medida da fenomenologia, discussões em que as conexões entre currículo, poder e ideologia são destacadas. Nessa perspectiva, por vezes estabelece-se uma linha do tempo na história do pensamento curricular, como se o currículo tivesse evoluído das teorias tradicionais para as teorias críticas de enfoque moderno e estruturalista para em seguida avançar para as teorias póscríticas".
} 
Pressupõe-se diversas tensões e contradições existentes na escola contemporânea e a relação entre conhecimento científico e conhecimento cotidiano pode ser encarada como uma dessas tensões. Se de um lado se tem a pluralidade cultural, do outro temos o conhecimento científico presente no cotidiano escolar. Como articular tais demandas? O que se entende por conhecimento? E pela adjetivação escolar? Assume-se aqui um risco, proposto como forma de compreensão de um objeto de estudo, qual seja pensar o conhecimento escolar como imaginação da cultura, entre os deslocamentos do crítico e do pós-crítico. Embora haja uma distinção clara entre tais correntes, opta-se por trabalhar na fronteira. Destaca-se, também, a ideia de que na fronteira há limites e possibilidades de alargamento do horizonte, contudo, há conflitos e disputas.

O debate sobre o conhecimento escolar, caro aos pesquisadores no Brasil a partir da década de 1980, ganha forma e relevância em um contexto histórico marcadamente no centro das mudanças sociais e políticas no mundo contemporâneo. A escola passa a ser uma arena de disputas diante de campos teóricos, a saber, a teoria da carência cultural; a teoria da Reprodução; a pedagogia crítico-social dos conteúdos; pedagogia libertadora, enfim, um sem-número de discursos sobre e para a escola (MATTOS, 2009). Forquin (1993), na década de 1990, indica que o papel social exercido pela escola é a transmissão dos conhecimentos acumulados pela humanidade às gerações futuras.

[...] Mesmo desencantados, mesmo desenganados, não podemos nos subtrair à continuidade das gerações e que estamos determinados a ensinar, estamos determinados a transmitir alguma coisa que valha para os que nos seguem, não porque achemos que o mundo se tornará especialmente, por isso, mais feliz, mais justo ou mais sábio, mas muito simplesmente porque o mundo continua (FORQUIN, 1993, p. 172).

Lopes (1999), elucida pressupostos centrais para se pensar questões relativas ao conhecimento escolar: i) os problemas de ensino-aprendizagem vinculados não ao processo metodológico, mas ao processo de construção social do conhecimento; ii) questões epistemológicas em uma perspectiva relativista por meio de um ponto de vista problematizador; iii) a escola como campo da centralidade do conhecimento e da cultura; iv) uma perspectiva pluralista da cultura contribuindo para diferentes saberes sociais; v) dimensão produtiva do conhecimento escolar por meio de produção e transposição didática, a escola é entendida como criadora de conhecimento e habitus. 
Partindo do presente contexto, o conhecimento escolar é posto em uma arena entre diferentes campos de estudo, Currículo e Didática, por exemplo, mas aqui, também, é situado numa abordagem socioantropológica da educação. Assim, retoma-se uma questão de fundo sobre qual seria a função social da escola: transmissão de conhecimento ou de cultura?

Questiona-se o que se ensina e como se ensina no âmbito escolar. Culpa-se pelo sucesso ou fracasso docentes e discentes (MATTOS, 2009), mas, quais disputas e deslocamentos estão presentes em tais processos? É preciso compreender que entre a luta de classes, no campo marxista, ou mesmo, a discursividade no âmbito pós-estruturalista encontram-se ressonâncias sobre aspectos do que seria conhecimento no âmbito escolar. "A escola reproduz, mas também resiste, e nesse campo de contradições precisamos trabalhar para: socializar o conhecimento científico, dialogar com os saberes populares e desconstruir a valorização ideológica do conhecimento científico feita na escola" (LOPES, 1999, p.24).

O conhecimento escolar é, então, entendido como espaço e tempo de contradição no âmbito da escola. Nas palavras de Lopes (1999, p. 25), "trata-se de um conhecimento selecionado a partir de uma cultura social mais ampla, que passa por um processo de transposição didática, ao mesmo tempo que é disciplinarizado; e também podemos entender que "constitui-se no embate com os demais saberes sociais, diferenciando-se dos mesmos. Em síntese, o conhecimento escolar define-se em relação aos demais saberes sociais, seja o conhecimento científico, o conhecimento cotidiano ou os saberes populares" (idem).

A disputa presente no significante conteúdo é um indicativo de que os mesmos são entendidos como "unidade diferencial que quando incorporada na cadeia de equivalência que fixa o sentido de escolar garante uma dimensão da recontextualização didática do conhecimento científico produzido e legitimado em função dos respectivos regimes de verdade das diferentes áreas disciplinares (GABRIEL; MORAES, 2014, p. 32).

Há circularidades de definições para o conhecimento, segundo Gabriel (2016), que nos ajudam a perceber as disputas e nuances nos significantes postos em justaposição ao ato de conhecer. Assim, i) conhecimento pode ser encarado como conteúdo e significado com conteudismo, cientificismo ou universalismo; ii) conhecimento pode ser entendido como experiência e significado com cotidiano, ecologia de saberes, tradução, saber; iii) conhecimento pode ser cultura e significado como negociação cultural, tradução, hibridismo; por fỉm, iv) 
conhecimento pode ser ciência e significado numa perspectiva universalista, verdadeira e legítima. É na disputa entre ambos os sentidos que pressupõe-se a emergência de novos outros.

Conteúdo é entendido como um conhecimento cientifico disciplinarizado, ou seja, um conhecimento que passou por um processo de recontextualização no modelo disciplinar no âmbito do currículo (GABRIEL; MORAES, 2014). As Diretrizes Curriculares Nacionais de 2010 afirmam que Art.9 - $3^{\circ}$ "Os conhecimentos escolares são aqueles que as diferentes instâncias que produzem orientações sobre o currículo, as escolas e os professores selecionam e transformam a fim de que possam ser ensinado e apreendidos" (DCN, Resolução 07, de 14 de dezembro de 2010).

Já no aspecto cultural, é assumida a ideia de Appadurai (2010) que entende a cultura como uma fotografia do real, que por si é compreendia como um constante fluxo de transição, ou seja, que há fluxos culturais em movimentos. Posto isso, reafirma-se a ideia de cultura para além dos sentidos partilhados, mas cultura como produção de sentidos e significados, como enunciação. Nas palavras de Lopes e Macedo (2011, p. 186), “como prática de enunciação e atribuição de sentidos". A cultura para as autoras pode ser entendida como negociação, produzida como símbolos e sentidos em ambivalência que envolve negar e aceitar ao mesmo tempo (LOPES E MACEDO, 2011).

Como argumenta Bernstein (1996), a forma como as sociedades selecionam, classificam, distribuem, transmitem e avaliam os saberes escolares reflete a distribuição de poder no interior destas mesmas sociedades e revela os mecanismos que asseguram o controle social dos comportamentos dos indivíduos. Revelam aspectos culturais. Ainda, nas palavras do autor "faz com que as relações de poder sejam expressas em termos de discurso e o discurso em termos de relações de poder" (BERNSTEIN, 1996, p. 190).

O conhecimento, então, assume articulações necessárias por meio das quais o conjunto da experiência humana torna-se inteligível a tantos outros possíveis. As formas de conhecer são fundamentais para a realização da mente humana. Mas, é preciso compreender que o conhecimento não corresponde, apenas, ao conjunto de inúmeras expressões simbólicas testadas largamente, ele se articula às interações e discursos possíveis no campo social. "Adquirir conhecimento é aprender a compreender e experienciar o mundo por intermédio dessas formas de conhecimento, sem as quais isso não seria possível” (LOPES, 1999, p. 164). Isto implica um 
processo que envolve a experiência e articulação por esquemas conceituais possíveis no horizonte da vida cotidiana.

Lopes e Macedo (2011) advogam a ideia de que a discussão sobre o conhecimento no campo curricular oscila entre o relativismo da aceitação de múltiplos saberes como válidos e o universalismo de aceitação de alguns saberes como arautos da verdade. As autoras indicam que, nessa perspectiva, o currículo não é entendido como algo fixo, como um produto outorgado à escola. O currículo assume o sentido de disputa da própria luta pela produção de significados, ou seja, o currículo assim como o conhecimento são entendidos como produção cultural. Parte-se de um princípio de que o "currículo é um espaço-tempo em que sujeitos diferentes interagem, tendo por referência seus diversos pertencimentos, e que essa interação é um processo cultural que ocorre num lugar-tempo cujas especificidades me interessam estudar" (MACEDO, 2004, p 288).

Numa perspectiva crítica o debate sobre o que é "fundamental" de ser ensinado na escola está posto em centralidade. O conhecimento universal, também, torna-se fundamental. Gabriel e Moraes (2014) indicam que o significante universal, destaca o conhecimento e é entendido como modo de homogeneizar e determinar limites. Nas palavras de Charlot (2013) não se pode contribuir para uma mitigação pedagógica. É preciso assumir o papel da escola como lócus de socialização de saberes e as contradições existentes entre o processo histórico do conhecimento e das estruturas da organização social.

As teorias críticas, de forma geral, assumem a ideia que a escola deve transmitir um conhecimento especializado, social e culturalmente acumulado pela humanidade para as gerações futuras. Nas palavras de Young um (2007, p 1296): “[...] conhecimento independente do contexto que é, pelo menos potencialmente, adquirido na escola e é a ele que me refiro como conhecimento poderoso". É nessa concepção de escola que o autor afirma uma concepção de currículo e de escola "onde o mundo é tratado como um objeto de pensamento e não como um lugar de experiência" (YOUNG, 2011, p. 616).

A existência da escola e seu futuro como instituição moderna, ou mesmo pós-moderna, possui sentido porque tem por principal objetivo a produção/reprodução cultural, ou seja, transmitir e/ou socializar conhecimentos produzidos temporal, cultural e socialmente a uma determinada geração. Numa perspectiva pós-estruturalista pensa-se que tanto maior será seu significado político-epistemológico, quanto maior for sua capacidade de produção de significados 
e de formação de sujeitos. Contudo, tais sujeitos precisam ser entendidos e se entenderem como pessoas conscientes de seus papeis históricos e com capacidade reflexiva e atuante nas transformações em direção a relações sociais de não-exclusão econômica e cultural no sentido de uma autodeterminação (LOPES e MACEDO, 2011; ALVES, 2012).

A mediação didática existente no dia a dia da escola assume uma característica de possibilidade facilitadora do processo de ensinar e aprender o que seria científico. Tal processo de facilitação implica em uma relação entre aprender e ensinar a partir do cotidiano dos alunos e das alunas em articulação com a perspectiva da diferença.

"Em suma, o conhecimento escolar, que envolve a (re)construção do conhecimento científico, não pode perder de vista a (re)construção do conhecimento cotidiano. Se concebemos a historicidade do conhecimento cotidiano e, portanto, sua mudança em virtude das alterações nas relações com diferentes saberes sociais, devemos conceber a escola como instituição que tem por objetivo contribuir para questionar as concepções cotidianas de todos nós" (LOPES, 1999, p.232).

O conhecimento escolar aquele que é submetido a uma transformação, ou seja, que ele é traduzido com suas finalidades objetificadas no ensino e na aprendizagem, assumindo uma distância do saber de referência. Por isso mesmo, é preciso compreender, no chão da escola, as mediações existentes entre os saberes de referência e os saberes escolares. É no deslocamento entre ambos que situamos a emergência de uma perspectiva do processo de ensino-aprendizagem possível ao futuro da escola brasileira (LOPES e MACEDO, 2011). Compreender o conhecimento escolar é a possibilidade de compreender lógicas socioantropológicas existentes nas relações sociais contemporâneas, dito de outro modo, compreender as lógicas dos sujeitos sociais.

Cria-se como possibilidade reflexiva a ideia de que o conhecimento é posto em circularidade na escola. A circularidade é colocada, dessa forma, em destaque, no sentido de compreender as interdependências entre os diferentes saberes postos no contexto social que ocorrem através de uma reestruturação das próprias relações socioculturais (BORGES, 2011). Saberes que se hibridizam, se chocam e contradizem, saberes que postos em deslocamentos não são fixados a um sentido único (MACEDO, 2004a).

Penso nos currículos escolares como espaço-tempo de fronteira e, portanto, como híbridos culturais, ou seja, como práticas ambivalentes que incluem o 
mesmo e o outro num jogo em que nem a vitória, nem a derrota jamais serão completas. Entendo-os como um espaço-tempo em que estão mesclados os discursos da ciência, da nação, do mercado, os "saberes comuns", as religiosidades e tantos outros, todos também híbridos em suas próprias constituições. É um espaço-tempo em que os bens simbólicos são "descolecionados", "desterritorializados", "impurificados" num processo de fluidez (MACEDO, 2004b, p. 290).

O conhecimento escolar é situado entre as diversas fronteiras aqui apresentadas podendo ser entendido como fruto do borramento de tais fronteiras. Então, defende-se o argumento que o conhecimento escolar é um conhecimento borrado. Conhecimento escolar que pode ser entendido como atos de significação na medida que significar perpassa pelo entrecruzamento do conteúdo, da experiência, da cultura e da ciência. Entende-se que atos de significação incidem i) na experiência de ser afetado, assim, gerando novas formas de se pensar e repensar o mundo, pois os afetos são construções culturais, "e que não têm nenhuma consistência fora dessa construção" (FAVRET-SAADA, p. 155, 2005), e ii) na imaginação como prática social na fabricação da vida dos sujeitos, assumido a imaginação dos próprios sujeitos que fazem parte da escola (fora dela), geram novos tipos de política, novos tipos de expressão coletiva e novas necessidades de disciplina social (APPADURAI, 2003). A escola seria, então, essa comunidade imaginada que cria sentidos para seus sujeitos. E criando-os, também, os socializa quer seja em âmbito local e/ou global.

Ao passo que isso ocorre, nosso olhar se volta para perceber como as contradições postas se articulam gerando novos empasses e superando antigos dilemas. Pensar o conhecimento na escola não mais como um bloco dado e homogêneo, mas como lugar de negociação, reinvenção e possibilidades de novos horizontes. Entre o crítico e o pós-crítico, situamos o conhecimento escolar como reimaginação da cultura que articula em si diferenças.

\section{A escola moderna sob rasura: em xeque o conhecimento escolar}

A instituição escola tal qual conhecemos hoje, em especial na América Latina, é amparada em um modelo da Modernidade europeia. Sua função ora centrada na manutenção das ideias da modernidade, ora centrada na transmissão de conhecimentos acumulados e socialmente reconhecidos vem sofrendo desgastes (CANDAU, 2008). 
Diante de um impasse do que vem se chamando de crise da escola (CHARLOT, 2007), de uma escola sequestrada (DUBET, 1997), ou mesmo, a escola sob suspeita (GABRIEL, 2008). Enfim, assume-se a ideia de que tal instituição está sob rasura (HALL, 1997). Tais demandas impostas à escola demonstram que o projeto de modernidade em que ela está inserida vem passando por esgotamentos presentes em diversos discursos na sociedade, desde as políticas curriculares ao que se é propagado na grande mídia, de forma geral, "o modelo de escola vai mal".

De acordo com Appadurai (2003) a modernidade de agora vem sendo protagonizada por um sujeito comum, o cidadão, que vive num movimento iminente, mas sempre em contato com outros movimentos, interacionistas e/ou imagéticos mediados no mundo. Criam-se assim, vidas e mundos imaginados. Pode-se pensar que a escola é uma comunidade imaginada.

Entende-se que a instituição escola é imaginada porque cada sujeito nela presente e existente cria uma imagem de sua comunhão, pois cada um se apropria de maneira diferente dos símbolos e signos existentes no âmbito escolar. "É nessa direção que vejo, ao menos em parte, o futuro do estudo da imaginação como prática social. É a força social da imaginação, produzida como coisa central, material" (APPADURAI, 2010, p. 06).

Assim, cada perspectiva dos atores sociais que interagem na escola é percebida pela posição que ocupam em relação à cultura e ao momento histórico vivido (APPADURAI, 2003). De forma que, na perspectiva do autor, a cultura pode ser compreendida em algumas dimensões, a saber, i) como substantivo, assim sendo algo partilhado e coisificado; ii) como dimensão da diferença, assim sendo, como linguagem; iii) como identidade de grupo, ou seja, como fronteiras de diferenças. Defende-se aqui, ainda que de forma contingencial, a cultura como fronteiras de diferenças em disputas. Por que em disputas, estão em deslocamentos, tensões e conflitos. Assim também situa-se a escola.

Appadurai (2003) propõe, então, uma reflexão sobre os mundos imaginados na era da globalização a partir dos fluxos culturais: cenários étnicos, ideológicos, midiáticos, tecnológicos e financeiros. O autor aponta para formas fluidas e irregulares destas paisagens que são permeadas de sentidos políticos, econômicos, históricos, linguísticos etc, que variam de acordo com a perspectiva do ator social envolvido na ação. Como situar a escola diante de tais cenários? 
Como pensar a diferença como articulação da escola? Como situar o conhecimento dentro dos cenários na globalização?

Ao estudar a história das disciplinas escolares, Chervel (1990, p. 181) nos fala que "a escola ensina, sob esse nome, um sistema, ou melhor, uma combinação de conceitos mais ou menos encadeados entre si". Como lugar de ensino, chegamos a relação entre o que ensinar, para quem ensinar e como ensinar. Por isso mesmo, a ideia de disciplina escolar está ligada a "um modo de disciplinar o espírito, quer dizer de lhe dar os métodos e as regras para abordar os diferentes domínios do pensamento, do conhecimento e da arte" (CHERVEL, 1990, p. 180).

A função social da escola é pensada não de forma simplificada, mas através de uma totalidade ampla e complexa, a partir da perspectiva do outro e do conhecimento por ele produzido, ou a ele destinado. Chervel (1990) nos fala, então, das tensões entre o "saber erudito", o "saber ensinado" e a inércia que a escola está envolvida. Como elemento da modernidade, das exigências deste período e de uma reelaboração própria de suas normas e valores, a instituição escolar é uma tecnologia que não se pode importar (DUBET, 1997). Afinal de contas reafirma-se a ideia que a escola ainda é um lugar privilegiado de socialização do conhecimento escolar, mas que veio assumindo outras funções e sentidos (GABRIEL e MORAES, 2014).

A escola é entendida como lócus do saber que contribui para pensarmos em suas implicações nas práticas de fracasso escolar que existem no dia a dia da sala de aula (MATTOS, 2009). Os conhecimentos selecionados a serem ensinados põem em xeque o silenciamento de diversas formas de compreensão do mundo, de seus esplendores e das misérias da "ciência" (MIGNOLO, 2003).

O conhecimento, é encarado como uma potência criativa no âmago da instituição escolar como poder, sendo este imbricado na relação que a escola estabelece com a sociedade, desempenhando um papel formativo de sujeitos e, dessa forma, de uma cultura que irá atuar diretamente na vivência desses mesmos sujeitos na sociedade em que vivem.

Retorna-se a Appadurai (2003) para pensar que os fluxos disjuntivos podem ser espectros que caracterizam movimentos constantes de ideias, pensamentos, ideologias, tecnologias, imagens, entre outros, na era da globalização. Fluxos que não têm a mesma direção, antes de tudo, são disjuntivos. Não seria possível imaginar a escola dentro de um cenário em movimento? Ao passo que se propõe tais reflexões é importante destacar que o currículo escolar, mas não 
somente ele, vem se assumindo como fluxo de demandas. De tal forma, retorna-se à ideia de diferença como possibilidade de análise das múltiplas formas de imaginar o mundo.

A afirmação feita por sociólogos, de matrizes críticas, de que todo saber é produzido socialmente para propósitos particulares em contextos particulares é, hoje, relativamente incontroversa. Contudo, será que isso quer dizer que o que é escolhido para ser incluído no currículo num determinado momento "nada mais é do que aquilo que aqueles que estão em posição de poder decidem ser o saber?" (YOUNG, 2000, p. 13).

Quais conhecimentos estão presentes na escola de hoje? E quais são as tensões presentes no dia a dia da vida escolar? Talvez seja possível pensar que reimaginando a escola e o conhecimento emergirão incontáveis modos de projeção da vida cotidiana dos sujeitos. Nas palavras de Lopes (2008, p. 211) "Se é possível pensar no papel da imaginação, como já destaquei, na produção de novas hegemonias, há que se considerar outros modos de projetar as práticas nas escolas". Assim, é possível, também, reimaginar a escola e o conhecimento como dimensões do tempo presente em que se compreendam projetos de sociedade que sejam capazes de articular demandas possíveis aos sujeitos postos em situação de desigualdade.

\section{À GUISA DE CONCLUSÃO}

O presente texto articulou o conhecimento escolar como reimaginação da cultura entendo que tais dimensões estão pautadas a partir da ideia da escola como produtora de diferença. Numa proposta de análise pautada em deslocamentos, entre o crítico e o pós-crítico, assume-se que o conhecimento escolar é imaginação da cultura. Tal ideia é posta no sentido de compreensão da escola moderna que, estando sob rasura, vem apresentando chaves de análise importantes para repensarmos o papel do conhecimento num projeto de disputa de significação e hegemonias.

A primeira pista em destaque é que a escola está situada em um contexto de crise, mas não sua crise, antes de tudo, de uma crise da modernidade que a leva para uma discussão acerca do seu sentido. Os projetos que disputam a escola também permanecem presentes nos cenários de globalização contemporâneo tensionando os processos de fluxos de sentido em um alargamento da própria modernidade (APPADURAI, 2003). 
A segunda pista, versa sobre o questionamento do conhecimento escolar e a produção de sentidos e significados existentes sobre a instituição escola, nesse contexto, ainda é preciso compreender práticas e saberes escolares como forma analítica. A escola moderna está imersa numa arena em disputas de poder e saber que estão relacionadas com mudanças e transformações modernas e pós-modernas. O currículo, então, é "habitado por uma diferença que não se define como a oposição ao homogêneo, que penso ser possível tratá-lo como uma espécie de espaçotempo cultural liminar. Um espaço-tempo em que as culturas presentes negociam com "a diferença do outro", que explicita a insuficiência de todo e qualquer sistema de significação (MACEDO, 2004b, p. 291).

Por fim, o terceiro aspecto versa sobre a relação dos sujeitos da escola com o conhecimento escolar. Tal relação é posta em xeque na medida que "o desafio consiste na construção de um instrumental analítico que permita contemplar tanto a dimensão epistemológica quando a dimensão simbólica presente nos embates cotidianos entre sujeitos e saberes que integram o contexto escolar" (GABRIEL, 2013, p. 234). Ou seja, há que se escutar as vozes discentes e docentes, mas não somente elas, presentes no dia a dia do chão escolar como forma de compreensão da própria dinâmica escolar.

A instituição escola é chamada, então, a se situar em uma perspectiva de reimaginação do seu próprio conhecimento, podendo indicar que tal ação ocorra no plano cultural diante de uma perspectiva de política curricular. O desafio proposto é (re)pensar em novas formas de produção, novos modelos e imagens na/da escola, uma circularidade de saberes e práticas, enfim, uma educação associada ao modelo emancipatório e não desigual. Reafirma-se a ideia de Gabriel (2013, p. 240) que é preciso pensar a escola pública brasileira “(...) como um espaço político, ainda importante no cenário atual, na disputa ou negociação de projetos de sociedade nos limites do campo de possibilidades, ainda que contingenciais, em que eles são pensados".

\section{REFERÊNCIAS}

ALVES, W. B. A Escola no Espelho: as representações do aluno. Tese (Doutorado em Educação), Faculdade de Educação, Universidade Federal Fluminense, Niterói, 2012. 158 p. 
APPADURAI, A. Entrevista com Arjun Appadurai. Concedida a Bianca Freire-Medeiros e Mariana Cavalcanti. Berlin, 13 de junho de 2008, Est. His. Rio de Janeiro, vol.23, n.45, p. 187197, 2010.

APPADURAI, A. Museus são bons: o patrimônio em cena na Índia. Revista MUSAS, n. 03, p.10-26, 2007.

APPADURAI, A. Modernity at large: cultural dimensions of globalization. Minneapolis: University of Minnesota Press, (1996) ed.2003.

BERNSTEIN, B. A estruturação do discurso pedagógico. Classe, códigos e controle. Petrópolis: Vozes, 1996.

BHABHA, H. O local da Cultura. 4reimp. Belo Horizonte: EDUFMG, 2007.

BORGES, L. P. C. Tecendo diálogos \& construindo pontes: a formação docente entre a escola e a universidade. 2011. 132f. Dissertação (Mestrado em Educação) - Faculdade de Formação de Professores, Universidade do Estado do Rio de Janeiro, 2011.

CANDAU, Vera Maria (Org.). Reinventar a escola. 7ed.Petrópolis: Vozes, 2008.

CHARLOT, Bernard. A Mistificação pedagógica (nova tradução, novo prefácio). 3. ed. São Paulo: Cortez, 2013. v. 1. 415.

CHARLOT, Bernard. Educação e Globalização. Uma tentativa de colocar ordem no debate. Revista Sísifo (Lisboa), v. 4, p. 129-136, 2007.

CHERVEL, A. História das disciplinas escolares: reflexões sobre um campo de estudo. Revista Teoria \& Educação, n.2, p. 177-229, 1990.

DUBET, François. Quando o sociólogo quer saber o que é ser professor. Entrevista com François Dubet. Revista Espaço Aberto, maio/jun/jul/ago, n.5; set/out/Nov/dez, n.6; p. 222-231, 1997.

FORQUIN, Jean-Claude. Escola e cultura. As bases sociais e epistemológicas do conhecimento escolar. Porto Alegre: Artes Médicas, 1993.

GABRIEL, C. Conhecimento escolar e emancipação: uma leitura pós-fundacional. Revista Cadernos de pesquisa, v. 46, p. 104-130, 2016.

GABRIEL, Carmen Teresa; MORAES, L. M. S. Conhecimento escolar e conteúdos: possibilidades de articulação nas tramas da didatização. In: GABRIEL, Carmen Teresa; MORAES, Luciane Stumbo. (Org.). Currículo e Conhecimento: diferentes perspectivas teóricas e abordagens metodológicas. 1ed.Petrópolis: DePetrus/FAPERJ, 2014, v. 1, p. 23-42. 
GABRIEL, C. T. Conhecimento escolar, cultura e poder: desafios para o campo do currículo em tempos de "pós". In: MOREIRA, A.F.; CANDAU, V.M,. (Org.). Multiculturalismo. Diferenças Culturais e Praticas pedagógicas. 10ed.Petrópolis: Editora Vozes, 2013, v. 1, p. 212-245.

GABRIEL, Carmen Teresa. Conhecimento escolar, cultura e poder: desafios para o campo do currículo em "tempos pós". In: CANDAU, V. M. \& MOREIRA, A. F. Multiculturalismo, diferenças culturais e práticas pedagógicas. Editora Vozes, Petrópolis/RJ, 2008.

HALL, Stuart. A centralidade da cultura: notas sobre as revoluções culturais do nosso tempo. Educação \& Realidade, Porto Alegre, v. 22, n², p. 15-46, jul./dez. 1997.

LOPES, A. R. C.; MACEDO, E. Teorias de Currículo. 1. ed. São Paulo: Cortez, 2011. v. 1. $279 \mathrm{p}$.

LOPES, A. C. Conhecimento escolar e conhecimento científico: diferentes finalidades, diferentes configurações. In: LOPES, A. C. Currículo e epistemologia. Ed. Unijuí, p. 187-204, 2007.

LOPES, A. C. A articulação entre conteúdos e competências em políticas de currículo para o ensino médio. LOPES, A. C.; MACEDO, E. F.; TURA, M. L. R.; LEITE, C. (orgs). Políticas educativas e dinâmicas curriculares no Brasil e em Portugal. Petrópolis: RJ, DP et Allii: FAPERJ, p. 189-213, 2008.

LOPES, A. C. Conhecimento escolar: ciência e cotidiano. 1ed. Rio de Janeiro: Editora da UERJ, 1999. 236p.

MACEDO, E. F. Currículo, cultura e diferença. In: LOPES, A. C.; ALBA, A. (Orgs.). Diálogos curriculares entre Brasil e México. Rio de Janeiro: EdUerj, p. 83-104, 2014.

MACEDO, E. F. Currículo e hibridismo: para politizar o currículo como cultura. Educação em Foco (Juiz de Fora), Juiz de Fora, v. 8, n. 1 e 2, p. 13-30, 2004a.

MACEDO, E. Currículo como espaço-tempo de fronteira cultural. Revista Brasileira de Educação. v.11, n. 32, p. 285-292, 2004 b.

MATTOS, C. L. G. de. Etnografia na escola: duas décadas de pesquisa sobre o fracasso escolar no ensino fundamental. In: MATTOS, C. L. G \& FONTOURA, H. A. da. (Orgs). Educação e Etnografia: relatos de pesquisa. Rio de Janeiro, EdUERJ, p.11-30, 2009.

MIGNOLO, W. D. O pensamento liminar e a transformação do conhecimento. In: Histórias locais /projetos globais - colonialidade, saberes subalternos e pensamento liminar. Tradução de Solange Ribeiro de Oliveira. Belo Horizonte: Editora UFMG, 2003.

PEREIRA, T. V. Conhecimento escolar \& trabalho docente. In: Rita de Cassia Prazeres Frangella (org.). Currículo, formação e avaliação: redes de pesquisas em negociação. Curitiba: CRV, p. 31-45, 2016. 
YOUNG, M. O currículo do futuro: da nova sociologia da educação a uma teoria crítica do aprendizado. Campinas: Papirus, 2000.

YOUNG, M. Para que servem as escolas?. Educação \& Sociedade, Campinas, v. 28, n. 101, p. 1287-1302, 2007.

YOUNG, M. O futuro da educação em uma sociedade do conhecimento: o argumento radical em defesa de um currículo centrado em disciplinas. Revista Brasileira de Educação. v.16, n. 48, p. 609-623, 2011. 